\title{
Expression of FOXC2, PinX1, Ki-67 and Cyclin D1 in cutaneous cell carcinoma
}

\author{
HAIYING ZHAO $^{1}$, YUNFENG CAO ${ }^{2}$, GUOQIANG WANG ${ }^{2}$ and ZENGXIANG LUO ${ }^{3}$ \\ ${ }^{1}$ Department of Dermatology and Sexually Transmitted Disease, Binzhou City Center Hospital; ${ }^{2}$ Department \\ of Oncology, Binzhou City Center Hospital, Binzhou, Shandong 251700; ${ }^{3}$ Department of Dermatology, \\ Affiliated Hospital of Weifang Medical University, Weifang, Shandong 261031, P.R. China
}

Received February 10, 2017; Accepted May 5, 2017

DOI: $10.3892 / \mathrm{ol} .2017 .6244$

\begin{abstract}
We investigated the expression of FOXC2, PinX1, Ki-67 and Cyclin D1 in cutaneous cell carcinoma. We collected 30 cutaneous squamous cell carcinoma (SCC), 30 cutaneous basal cell carcinoma (BCC) and 30 normal skin tissues. The protein expression and gene expression of FOXC2, endogenous telomerase-inhibiting gene PinX1, Ki-67 and Cyclin D1 was measured by immunohistochemistry (IHC) and semi-quantitative reverse transcription polymerase chain reaction (RT-PCR), respectively. In SCC and BCC tissues, the positive rate of protein expression and mRNA level of PinX1 were both significantly lower than those in normal tissues. However, the positive rate of protein expression and mRNA level of FOXC2, Ki-67 and Cyclin D1 were significantly higher than those in normal tissues $(\mathrm{p}<0.05)$. There was no significant difference between SCC and BCC ( $\mathrm{p}>0.05)$. In conclusion, FOXC2 may participate in the carcinogenesis process of SCC and BCC. It may also correlate with the expression PinX, Ki-67 and Cyclin D1. However, FOXC2 alone cannot be used as a diagnostic indicator of SCC.
\end{abstract}

\section{Introduction}

In the white population of European and American countries, squamous cell carcinoma (SCC) is the second most common skin morbidity after basal cell carcinoma (BCC) (1). In China, there are $\sim 1.5-2.0$ million new cases a year, accounting for around $5-12 \%$ of all malignant tumors (1). The overall effects of various factors, such as ultraviolet (UV) exposure, autoimmune disease, inflammation and bruising are thought to play a role in the pathogenesis of cutaneous carcinoma (2).

Correspondence to: Dr Zengxiang Luo, Department of Dermatology, Affiliated Hospital of Weifang Medical University, 2428 Yuhe Road, Kuiwen, Weifang, Shandong 261031, P.R. China E-mail: c6158t@163.com

Key words: cutaneous squamous cell carcinoma, transcription factor FOXC2, endogenous telomerase-inhibiting gene PinX, Ki-67, Cyclin D1
Tumorigenesis is closely related with aberrant expression of transcription factors and proteins. The forkhead box (FOX) protein family is a highly evolutionary conserved protein family and includes a 7 same nucleotide core sequence motif [5'-(G/A)(T/C)(A/C)AA(C/T)A-3'], which regulates the expression of downstream target genes (3). FOXC2 regulates cell proliferation, differentiation and invasion, and lymphangiogenesis and angiogenesis in a variety of malignant tumors, including lung, breast and cervical cancers $(4,5)$. The endogenous telomerase-inhibiting gene PinX1, is a potential tumor suppressor that helps downregulate the activity of telomerase and shorten the telomere, inducing apoptosis of cancer cells (6). Ki-67, a proliferating cell nuclear antigen (PCNA), may indirectly reflect the proliferation of tumor cells (7). Cyclin D1, a positive regulator of cell cycle, also influences the proliferation activity of tumor cells (8). We hypothesized that the altered expression of FOXC2 in the skin plays a role in the underlying mechanism of SCC, and determined the expression of possible downstream factors whose expressions might also be changed in SCC tissues.

\section{Materials and methods}

Study objects. Pathology skin specimens from patients diagnosed with either SCC or BCC from October 2015 to October 2016 were used for experiments (thirty samples in each group). Additionally, thirty normal skin tissue samples were included as a control group.

Among SCC patients, there were 16 men and 14 women, aged from 35 to 68 years, with an average of $52.5 \pm 13.6$ years. The tumors were located at the head and face in 20 patients and in the limbs in 10 patients. TNM staging placed 6 patients in stage I, 10 patients in stage II, 3 patients in stage III and 3 patients in stage IV. The largest diameter of the tumors ranged from 0.3 to $3.5 \mathrm{~cm}$ (with an average of $1.6 \pm 0.9 \mathrm{~cm}$ ). According to classification by pathological grade, 3 patients were grade I, 6 were grade II, 12 grade III and 9 grade IV.

Among BCC patients, there were 14 men and 16 women, their ages ranged from 39-75, with an average of 54.4 \pm 16.7 years. A total of 22 patients had tumors in the head and face and 8 patients in the limbs. According to TNM staging, there were 5 patients in stage I, 8 patients in stage II, 13 patients in stage III and 4 patients in stage IV. The largest diameter 
of the tumors ranged from 0.2 to $3.2(1.4 \pm 0.7 \mathrm{~cm}$ on average $)$. According to pathological grading, there were 5 patients in grade I, 8 in grade II, 11 in grade III and 6 in grade IV.

Finally, in the control group there were 15 men and 15 women, their ages ranged from 30 to 70 years $(52.2 \pm 15.8$ years on average). A total of 16 normal tissues were taken from the head and face and 14 from the limbs.

The baseline data of all groups is comparable. This study was approved by the Ethics Committee of Affiliated Hospital of Weifang Medical University. Signed written informed consents were obtained from all participants before the study.

Immunohistochemistry (IHC). IHC was used to measure the protein expression of FOXC2, PinX, Ki-67 and Cyclin D1 in the skin specimens obtained. After fixing and paraffin embedding, the tissues were cut at $5 \mu \mathrm{m}$, then de-paraffinized and hydrated. The samples were incubated with $3 \%$ $\mathrm{H}_{2} \mathrm{O}_{2}$ solution for $20 \mathrm{~min}$ at $27^{\circ} \mathrm{C}$ for blocking, then incubated with normal goat serum working solution (Biosharp, Hefei, China) for $30 \mathrm{~min}$ at $27^{\circ} \mathrm{C}$. Next, the slices were incubated overnight at $4^{\circ} \mathrm{C}$ with mouse monoclonal FOXC2 antibody (dilution, 1:500; cat. no. SAB1412035), mouse monoclonal PinX1 antibody (dilution, 1:500; cat. no. SAB2500795), mouse monoclonal Ki-67 antibody (dilution, 1:500; cat. no. WH0004288M1), mouse monoclonal Cyclin D1 antibody (dilution, 1:500; cat. no. SAB4503500), all purchased from Sigma (St. Louis, MO, USA). Goat anti-mouse IgG secondary polyclonal antibodies (dilution, 1:1,000; cat. no. ab6789; Abcam, Cambridge, MA, USA) were used next for incubation at $27^{\circ} \mathrm{C}$ for $20 \mathrm{~min}$. Finally, the tissues were incubated with horse-radish peroxidase labelled streptavidin working solution at $27^{\circ} \mathrm{C}$ for $20 \mathrm{~min}$. The slices were washed with PBS 3 times, each for $5 \mathrm{~min}$, and DAB solution was added. The following procedures included hematoxylin staining, dehydrating, and mounting of the slices with neutral balsam. A microscope (BX-42; Olympus,Tokyo, Japan) was used to observe the staining of the target proteins on the tissues.

Slices were evaluated according to the staining intensity and the percentage of stained cells using semi-quantitative method. The staining intensity in both cytoplasm and nucleus was scored and stratified as follows: grade 0 (no staining or negative), grade 1, (light yellow or weak positive), grade 2 (yellow or moderate positive) and grade 3 (yellow-brown or strong positive). A staining score was defined as follows: score 0 (the number of positive cells $\leq 5 \%$ ), score 1 (6-25\% of cells were stained), score 2 (26-50\% of cells were stained), score 3 (51-75\% of cells were stained) and score 4 (>76\% of cells were stained). A final immunoreactivity score (IRS) was obtained for each case by multiplying the grade times the score. Protein expression levels were defined as negative if the IRS equaled 0-3, or positive if the IRS value equaled 4-12.

Reverse transcription polymerase chain reaction ( $R T-P C R)$. Semi-quantitative RT-PCR was used to measure the gene expression of FOXC2, PinX, Ki-67 and Cyclin D1.

Total RNA samples were extracted from each specimen with TRIzol solution (ZSGB-Bio, Beijing, China). The purity and concentration of total RNA samples were verified with an ultraviolet spectrophotometer (Europe B.V., Venlo, The Netherlands). cDNA was synthesized with a reverse
Table I. RT-PCR primer sequences.

\begin{tabular}{ll}
\hline Genes & \multicolumn{1}{c}{ Primer sequences } \\
\hline FOXC2 & F: 5'-GCCGACGGATTCCTGCGCTC-3' \\
& R: 5'-CGCTCCTCGCTGGCTCCA-3' \\
PinX1 & F: 5'-GGTGGTCTAAAGGAAAGGGTTT-3' \\
& R: 5'-ATGGGCAATCCAGTTGTCTT-3' \\
Ki-67 & F: 5'-GAGAATCTGTGAATCTGGGTAA-3' \\
& R: 5'-CAGGCTTGCTGAGGGAAT-3' \\
Cyclin D1 & F: 5'-GGTTTCATCCAGGATCGAGCAGG-3' \\
& R: 5'-ACAAAGATGGTCACGGTCTGCC-3' \\
GAPDH & F: 5'-CGCGAGAAGATGACCCAGAT-3' \\
& R: 5'-GCACTGTGTTGGCGTACAGG-3' \\
\hline
\end{tabular}

transcription kit (Takara Bio, Inc., Otsu, Japan) according to the manufacturer's instructions. Primers were designed according to the Gene Bank sequences and they were purchased from Sangon Biotech (Shanghai, China). RT-PCR primer sequence information is shown in Table I.

A total of $25 \mu \mathrm{l}$ reactions were prepared for each RT-PCR containing $2 \mu \mathrm{l}$ cDNA, $3 \mu \mathrm{l}$ of F-primer, $3 \mu \mathrm{l}$ of R-primer, $0.5 \mu 1$ of Taq DNA polymerase, $1 \mu 1$ of dNTPs and $3 \mu 1$ of $\mathrm{MgCl}_{2}$. An initial amplification using primers was done with a denaturation step at $95^{\circ} \mathrm{C}$ for $5 \mathrm{~min}$, followed by 30 repeated cycles of $95^{\circ} \mathrm{C}$ for $30 \mathrm{sec}, 58^{\circ} \mathrm{C}$ for $30 \mathrm{sec}$ and $72^{\circ} \mathrm{C}$ for $60 \mathrm{sec}$. A final elongation step at $72^{\circ} \mathrm{C}$ for $10 \mathrm{~min}$ followed. Next, $2 \%$ agarose gel electrophoresis was used to identify the PCR products by their predicted size. Analyze the grey level using ultraviolet spectrometry imaging with gel imaging analysis system (Applied Biosystems Life Technologies, Foster City, CA, USA). The result was measured by the method of $2^{-\Delta \Delta C q}$.

Statistics analysis. SPSS 20.0 software (SPSS Inc., Chicago, IL, USA) was used to conduct the statistical analyses. The numeric data were expressed as mean \pm standard deviation. One-way analysis of variance (ANOVA) was used to assess the difference between groups. LSD t-test was used to compare the mean between two groups. Case number or \% was used to indicate categorical data. $\chi^{2}$ test was used for comparison between groups. It was considered as statistically significant at $\mathrm{p}<0.05$.

\section{Results}

Protein expression of FOXC2, PinX, Ki-67 and Cyclin D1. The expression levels of PinX1 in SCC and BCC were significantly lower than that in normal skin tissues. However, the protein expression levels of FOXC2, Ki-67 and Cyclin D1 were significantly higher than those of normal tissues $(\mathrm{p}<0.05)$. There was no significant correlation between SCC and BCC ( $>0.05$, Fig. 1 and Table II). The expression level of PinX1 in SCC and BCC tissues was significantly lower than that of normal tissues, while the protein expression levels of FOXC2, Ki-67 and Cyclin D1 were significantly higher than those in normal tissues. No significant correlation was observed between SCC and BCC. 
Table II. Protein expression of PinX1, FOXC2, Ki-67 and Cyclin D1 [n (\%)]

\begin{tabular}{|c|c|c|c|c|c|}
\hline Group & $\mathrm{n}$ & PinX1 & FOXC2 & $\mathrm{Ki}-67$ & Cyclin D1 \\
\hline SCC & 30 & $6(20.0)$ & $22(73.3)$ & $20(66.7)$ & $18(60.0)$ \\
\hline $\mathrm{BCC}$ & 30 & $8(26.7)$ & $21(70.0)$ & $18(60.0)$ & $16(53.3)$ \\
\hline Normal & 30 & $24(80.0)$ & $10(33.3)$ & $6(20.0)$ & $8(26.7)$ \\
\hline$\chi^{2}$ & & 26.599 & 12.208 & 15.296 & 7.500 \\
\hline P-value & & $<0.001$ & 0.002 & $<0.001$ & 0.024 \\
\hline
\end{tabular}

SCC, squamous cell carcinoma; BCC, basal cell carcinoma.
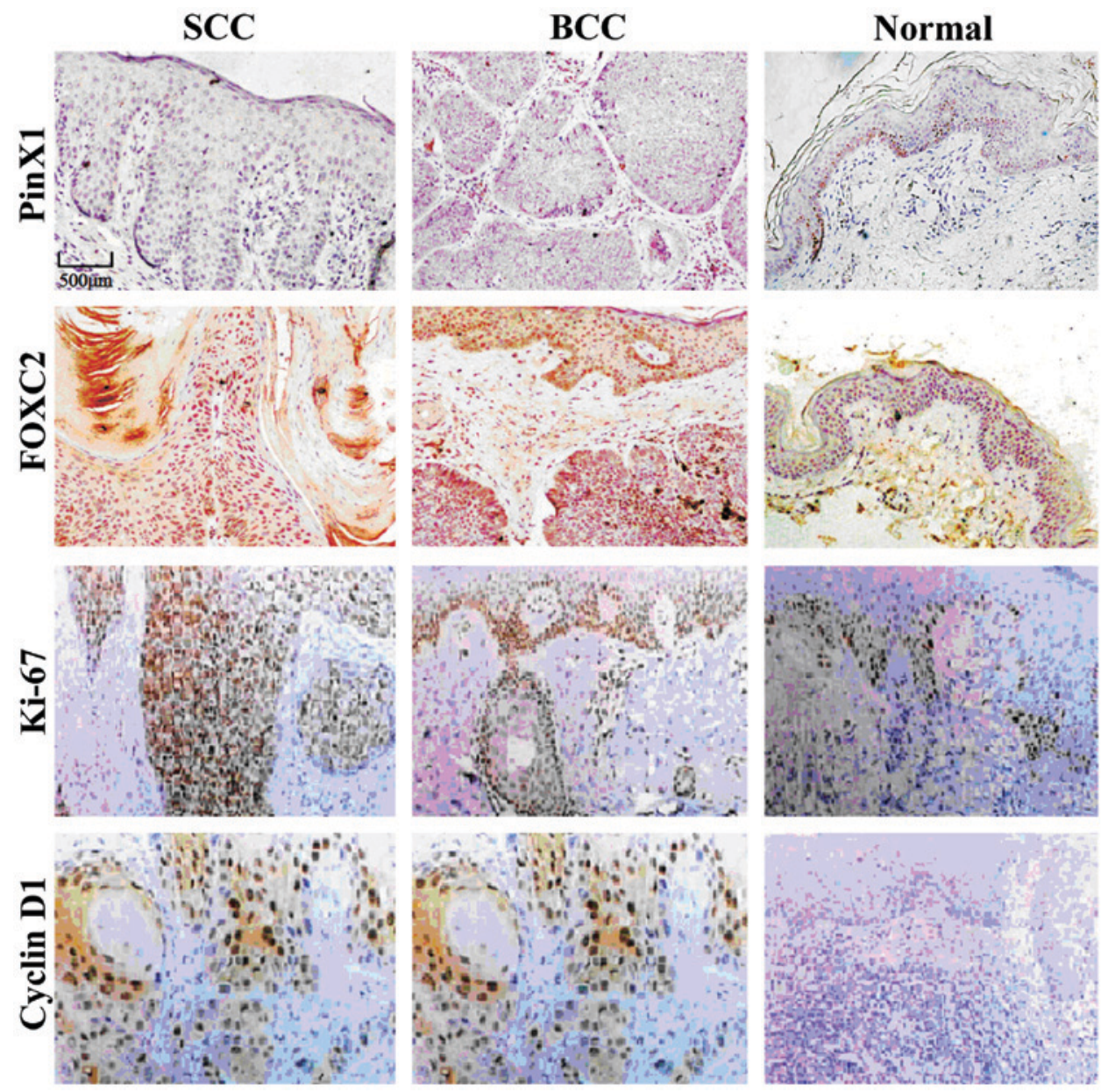

Figure 1. IMC for expression of PinX1, FOXC2, Ki-67 and Cyclin D1.

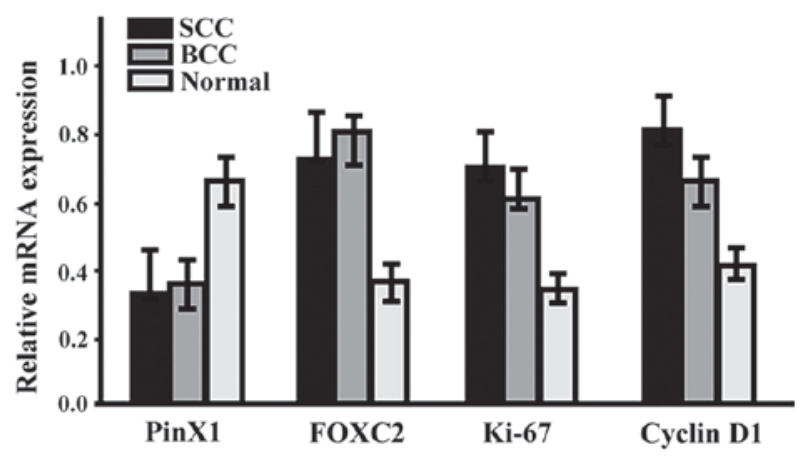

Figure 2. mRNA expression of PinX1, FOXC2, Ki-67 and Cyclin D1 by RT-PCR.
The gene expression of PinX1, FOXC2, Ki-67 and Cyclin D1. The mRNA expression level of PinX1 in SCC and BCC was significantly lower than that in normal tissues, while the mRNA expression levels of FOXC2, Ki-67 and Cyclin D1 were significantly higher than those in normal tissues $(\mathrm{p}<0.05)$. No significant correlation between SCC and BCC was observed (p $>0.05$, Fig. 2).

\section{Discussion}

Researchers have found FOXC2 expressed in the vascular endothelium of human and murine melanomas (9). After hypodermic injection of malignant melanoma tumor cells into wild-type 
and FOXC2 heterozygous mutant $\left(\mathrm{FOXC}^{+/}\right) \mathrm{B} 16$ mice, it was clear that the tumor growth and angiogenesis in the mutant mice was significantly slower than the same in the wild-type mice, suggesting that FOXC2 plays critical roles in tumor angiogenesis. FOXC2 inhibits apoptosis of vascular endothelium by increasing the expression of vascular endothelium growth factor A (VEGF-A) (10). In addition, FOXC2 sets up a local tumor microenvironment by enhancing the secretion and expression of matrix metalloproteinase-2 (MMP-2), stromal-derived factor-1 (SDF-1) and some other active molecules (11). Moreover, FOXC2 has been shown to be involved in tumor invasion and metastasis, as well as in the development of the epithelial-mesenchymal transition (EMT) observed in many tumors (12).

In this study, both the protein and mRNA levels of PinX1 in SCC and BCC were significantly lower than those in normal skin tissues, while the expression rates of FOXC2, $\mathrm{Ki}-67$ and Cyclin D1 were higher than those of normal tissues $(\mathrm{p}<0.05)$. However, no significant differences were found when comparing levels between SCC and BCC ( $>0.05)$. This evidence indicates that FOXC2 may be involved in the development of SCC and BCC and (based partly on prior literature) it may do so by changing the levels of PinX1, Ki-67 and Cyclin D1 in turn. However, FOXC2 cannot be used as a specific biomarker to diagnose SCC. Nevertheless, the levels of FOXC2 combined with clinical features of various malignant tumors, may serve as a valuable biomarker for early diagnosis and prognosis (13).

PinX1 can directly interact with human telomerase reverse transcriptase (hTERT), which is a key speed-limiting enzyme for the activity of telomerase (6). PinX1 is widely expressed in human tissue and mostly locates in the cell nucleolus and telomere proximity. However, the expression of PinX1 in tumor tissues is limited at best (14). Ki-67 correlates with the aggressiveness of a tumor (15), and can thus be used as an objective indicator of the proliferation activity of an SCC. Cyclin D1, on the other hand, is a key factor regulating cell cycle of both normal and tumorigenic cells and its expression correlates with tumor proliferation and differentiation (16).

We hypothesized that the altered expression of FOXC2 in the skin plays a role in the underlying mechanism of SCC, and determined the expression of possible downstream factors whose expression might also be changed in SCC tissues. The aim of this investigation was to show the role of FOXC2 in the development of SCC and BCC. Additionally FOXC2 may promote the tumor development by affecting the expression level of PinX1, Ki-67 and Cyclin D1, which could be an important mechanism of oncogenesis and be used as an early intervention in SCC. We intend to further analyze the correlation between FOXC2 and the clinical features of SCC and $\mathrm{BCC}$. The reason why there is no significant difference of FOXC2 expression between $\mathrm{SCC}$ and $\mathrm{BCC}$ remains to be explored. The small sample size of this study may influence the results. We plan to adopt methods of in vitro gene expression silencing or the overexpression of genetic vectors to further explore the specific mechanism of FOXC2-induced tumorigenesis.

\section{References}

1. Farasat S, Yu SS, Neel VA, Nehal KS, Lardaro T, Mihm MC, Byrd DR, Balch CM, Califano JA, Chuang AY, et al: A new American Joint Committee on Cancer staging system for cutaneous squamous cell carcinoma: Creation and rationale for inclusion of tumor $(\mathrm{T})$ characteristics. J Am Acad Dermatol 64: 1051-1059, 2011.

2. Kwon S, Dong ZM and Wu PC: Sentinel lymph node biopsy for high-risk cutaneous squamous cell carcinoma: Clinical experience and review of literature. World J Surg Oncol 9: 80, 2011.

3. Shimeld SM, Degnan B and Luke GN: Evolutionary genomics of the Fox genes: Origin of gene families and the ancestry of gene clusters. Genomics 95: 256-260, 2010.

4. Jiang W, Fan H, Qian C, Ding J, Wang Q and Pang X: Prognostic value of high FoxC2 expression in resectable non-small cell lung cancer, alone or in combination with E-cadherin expression. BMC Cancer 16: 16, 2016.

5. Werden SJ, Sphyris N, Sarkar TR, Paranjape AN, LaBaff AM, Taube JH, Hollier BG, Ramirez-Peña EQ, Soundararajan R, den Hollander P, et al: Phosphorylation of serine 367 of FOXC2 by 338 regulates ZEB1 and breast cancermetastasis, without impacting primary tumor growth. Oncogene 35: 5977-5988, 2016.

6. Lai XF, Shen CX, Wen Z, Qian YH, Yu CS, Wang JQ, Zhong PN and Wang HL: PinX1 regulation of telomerase activity and apoptosis in nasopharyngeal carcinoma cells. J Exp Clin Cancer Res 31: 12, 2012.

7. Sobecki M, Mrouj K, Camasses A, Parisis N, Nicolas E, Llères D, Gerbe F, Prieto S, Krasinska L, David A, et al: The cell proliferation antigen Ki-67 organises heterochromatin. eLife 5: e13722, 2016.

8. Dong M, Wei H, Hou JM, Gao S, Yang DZ, Lin ZH, Jia Y, Ren XP and Gao MH: Possible prognostic significance of p53, cyclin D1 and $\mathrm{Ki}-67$ in the second primary malignancy of patients with double primary malignancies. Int J Clin Exp Pathol 7: 3975-3983, 2014.

9. Sano H, Leboeuf JP, Novitskiy SV, Seo S, Zaja-Milatovic S, Dikov MM and Kume T: The Foxc2 transcription factor regulates tumor angiogenesis. Biochem Biophys Res Commun 392: 201-206, 2010.

10. Sasahira T, Ueda N, Yamamoto K, Kurihara M, Matsushima S, Bhawal UK, Kirita T and Kuniyasu H: Prox1 and FOXC2 act as regulators of lymphangiogenesis and angiogenesis in oral squamous cell carcinoma. PLoS One 9: e92534, 2014.

11. Li D, Yan D, Liu W, Li M, Yu J, Li Y, Qu Z and Ruan Q: Foxc2 overexpression enhances benefit of endothelial progenitor cells for inhibiting neointimal formation by promoting CXCR4-dependent homing. J Vasc Surg 53: 1668-1678, 2011.

12. Hollier BG, Tinnirello AA, Werden SJ, Evans KW, Taube JH, Sarkar TR, Sphyris N, Shariati M, Kumar SV, Battula VL, et al: FOXC2 expression links epithelial-mesenchymal transition and stem cell properties in breast cancer. Cancer Res 73: 1981-1992, 2013.

13. Nishida N, Mimori K, Yokobori T, Sudo T, Tanaka F, Shibata K, Ishii H, Doki Y and Mori M: FOXC2 is a novel prognostic factor in human esophageal squamous cell carcinoma. Ann Surg Oncol 18: 535-542, 2011.

14. Zhou XZ and Lu KP: The Pin2/TRF1-interacting protein PinX1 is a potent telomerase inhibitor. Cell 107: 347-359, 2001.

15. Bedir R, Güçer H, Şehitoğlu I, Yurdakul C, Bağc1 P and Üstüner P: The role of p16, p21, p27, p53 and Ki-67 expression in the differential diagnosis of cutaneous squamous cell carcinomas and keratoacanthomas: An immunohistochemical study. Balkan Med J 33: 121-127, 2016.

16. Shen Y, Xu J, Jin J, Tang H and Liang J: Cyclin D1 expression in Bowen's disease and cutaneous squamous cell carcinoma. Mol Clin Oncol 2: 545-548, 2014. 